REF - ISSN 1808-0804 Vol. VIII (2), 60 - 74, 2011

\title{
USO DE MARCADORES TUMORAIS NO DIAGNÓSTICO E ACOMPANHAMENTO DO TRATAMENTO DO CÂNCER
}

USE OF TUMOR MARKERS IN THE DIAGNOSIS AND MONITORING OF THE TREATMENT OF CANCER

USO DE MARCADORES DE TUMOR EN EL DIAGNÓSTICO Y SEGUIMIENTO DEL TRATAMIENTO DEL CÁNCER

\author{
Gyzelly Gondim de Oliveira ${ }^{1}$ e Cristiane Alves da Fonseca ${ }^{2}$ \\ ${ }^{1}$ Discente do Curso de Farmácia, da Universidade Estadual de Goiás - UEG \\ ${ }^{2}$ Docente do Curso de Farmácia,Universidade Estadual de Goiás -UEG \\ E-mail do autor para correspondência: gyzellygo@hotmail.com
}

\section{Recebido em 25/08/2010, Aceito em 20/05/2011}

RESUMO: Marcadores tumorais são macromoléculas de caráter protéico presentes em tumores, no sangue e em outros líquidos biológicos. O aparecimento dos marcadores ou aumento na concentração destes pode ser indicativo de gênese e crescimento de células neoplásicas. Os marcadores tumorais são úteis no manejo clínico dos pacientes com câncer, auxiliam nos processos de diagnóstico, estadiamento, avaliação da resposta terapêutica e detecção de recidivas. Podem ser detectados e quantificados na corrente sangüínea, líquidos biológicos e tecidos. As principais técnicas de detecção dos marcadores são as técnicas de citometria de fluxo e Imuno-Histoquímica. Entre os principais marcadores tumorais, quantificados pela técnica de imuno-histoquímica, estão: Alfafetoproteína, Beta-HCG, CA 19.9, CA 125, Calcitonina, Catepsina D; CEA (Antígeno carcinoembrionário), CYFRA 21.1, Proteína p53, PSA (Antígeno prostático específico). O Marcador ideal é aquele produzido por todos os tumores da mesma linhagem e seus níveis são mensuráveis mesmo na presença de pequenas quantidades de células. Os níveis séricos devem refletir com precisão a evolução clínica, a regressão da doença, e sua remoção deve estar associada à cura. Este estudo possui o objetivo de analisar e discutir a importância dos marcadores tumorais no tratamento e diagnóstico do câncer. 
De Oliveira, G. G., Da Fonseca, C. A. / Revista Eletrônica de Farmácia Vol VIII (2), 60 74,2011

Palavras - Chave: Malignidade. Proteínas. Detecção. Resposta terapêutica.

ABSTRACT: Tumor markers are protein macromolecules character present in tumors, blood and other biological fluids. The appearance of the markers or its concentration increase may be indicative of the genesis and growth of neoplastic cells. Tumor markers are useful in the clinical management of cancer patients and assist in the processes of diagnosis, staging, assessment of therapeutic response and detection of recurrence. It can be detected and quantified in the bloodstream, body fluids and tissues. The main techniques for detection of the markers are the techniques of flow cytometry and immunohistochemistry. Among the main tumor markers, quantified by the technique of immunohistochemistry, are: Alpha-fetoprotein, beta-HCG, CA 19.9, CA 125, calcitonin, cathepsin D; CEA (carcino-embryonic antigen), CYFRA 21.1, p53 protein, PSA (Antigen Prostate-specific). The ideal marker is one produced by all tumors of the same lineage and their levels are measurable even in the presence of small amounts of cells. Serum levels should accurately reflect the clinical outcome, the regression if the disease and their removal must be associated with healing. His study is to analyze and discuss the importance of tumor markers in cancer diagnosis and treatment.

Keywords: Malignancy. Proteins. Detection. Therapeutic response.

RESUMEN: Marcadores tumorales son macromoléculas de carácter proteico presente en tumores en la sangre y en otros líquidos biológicos. La aparición de los marcadores o aumento en la concentración de estos puede ser indicativo de génesis y crecimiento de células neoplasticas. Los marcadores tumorales son útiles en el manejo clínico de los pacientes con cáncer, ayudan en los procesos de diagnostico, estadiamiento, evaluación de la contestación terapéutica y detección de recidivas. Pueden ser detectados y cuantificados en la corriente sanguínea, líquidos biológicos y tejidos. Las principales técnicas de detención de los marcadores son las técnicas de citometria de flujo y Imuno-Histoquimica. Entre los principales marcadores tumorales, cuantificados por la técnica de Imuno-Histoquimica, están: Alfafetroproteina, Beta-HCG CA 19.9, CA 125, Calcitonina, Catepsina D; CEA (Antígeno carcino-embrionário), CYFRA 21.1, Proteína p53, PSA. El marcador ideal es aquel producido por todos los tumores de la misma linaje y sus niveles son mensurables aunque en la presencia de pequeñas cantidades de células. Los niveles séricos deben reflejan con precisión la evolución, la regresión de la enfermedad, y su remoción debe estar asociada a la cura. Ese estudio posee el objetivo de analizar y discutir la importancia de los marcadores tumorales en el tratamiento y diagnostico del cáncer.

Palabras - Clave: Malignidad, Proteínas, Detección, Contestación Terapéutica

\section{INTRODUÇÃO}

Marcadores tumorais são proteínas, incluindo antígenos de superfície celular, proteínas citoplasmáticas, enzimas e hormônios. São produzidos diretamente pelo tumor ou pelo organismo em 
De Oliveira, G. G., Da Fonseca, C. A. / Revista Eletrônica de Farmácia Vol VIII (2), 60 74,2011

resposta a presença da neoplasia. Podem ser detectados e quantificados na corrente sanguínea, fluidos biológicos e tecidos. A detecção nos tecidos é realizada por método de imunohistoquímica, com o objetivo de facilitar o diagnóstico diferencial das neoplasias. Cada marcador tumoral tem um valor de referência determinados; taxas acima do valor de referência apresentados por pacientes devem ser investigados ${ }^{(1)}$.

São úteis no manejo clínico dos pacientes com câncer, auxiliam nos processos de diagnóstico, prognósticos, estadiamento, avaliação da resposta terapêutica, detecção de recidivas durante o período de acompanhamento, localização de metástases, detecção precoce de recorrência e nos tratamentos com imunorradioterapia ${ }^{(2)}$.

Considera-se como marcador ideal aquele produzido por todos os tumores da mesma linhagem e seus níveis é mensurável mesmo na presença de pequenas quantidades de células. Os níveis séricos devem refletir com precisão e evolução clínica e a regressão da doença, e sua remoção deve estar associada à cura. Porém nenhum marcador estudado até o momento possui todas essas características, pecam por falta de especificidade $e$ sensibilidade, pois os marcadores tumorais não são considerados isoladamente. Os valores de diagnóstico e prognóstico dos marcadores são concluídos considerando-se um painel de marcadores, cujo significado leva em considerações variáveis intrínsecas ao paciente e ao seu histórico de vida ${ }^{(3)}$.

\section{METODOLOGIA}

Para o presente trabalho de revisão foram realizadas buscas nas bases eletrônicas de dados: Scielo, BIREME, MEDLINE, Periódico CAPES sobre a importância dos marcadores tumorais no diagnóstico e tratamento do câncer e em livros da área médica que possuíam o assunto abordado.

\section{Critérios de inclusão}

Artigos indexados, publicados nos anos de 2001 a 2009, monografias e textos clássicos sobre os marcadores tumorais utilizados no diagnóstico e tratamento das neoplasias. Foram focados artigos recentes cujo escopo estão, principalmente, associados à utilização dos marcadores tumorais na prática clínica.

\section{Critérios de exclusão}

Utilizou como critérios de exclusão os artigos e dados com data inferior ao ano 2001.

\section{RESULTADOS}

No presente trabalho serão focados resumidamente os principais marcadores tumorais em uma perspectiva clínica (Quadro 1). Dentre esses marcadores, encontram-se os marcadores ImunoHistoquímicos: Alfafetoproteína, Antígeno Carcinoembrionário (CEA), Antígeno prostático específico (PSA), CA 15-3, CA 19.9, Catepsina D, C-erbB-2, 
De Oliveira, G. G., Da Fonseca, C. A. / Revista Eletrônica de Farmácia Vol VIII (2), 60 74,2011

CYFRA 21.1, Proteína p53, Proteína RB, PCNA, e Tireoglobulina ${ }^{(1)}$.

Enolase Neurônio -Especifico (NSE)

\begin{tabular}{|c|c|c|c|}
\hline Marcador & $\begin{array}{l}\text { Indicação mais } \\
\text { freqüente }\end{array}$ & Outras situações & Principal Aplicação \\
\hline AFP & $\begin{array}{l}\text { Câncer hepatocelular, } \\
\text { tumores de células } \\
\text { germinativas. }\end{array}$ & Cirrose e hepatite & Avaliação de tratamento \\
\hline CA 15.3 & Câncer de mama & $\begin{array}{c}\text { Patologias hepáticas } \\
\text { benignas }\end{array}$ & $\begin{array}{c}\text { Seguimento de câncer de } \\
\text { mama }\end{array}$ \\
\hline CA 19.9 & $\begin{array}{c}\text { Carcinomas trato } \\
\text { digestivo Pâncreas } \\
\text { Trato Biliar } \\
\end{array}$ & $\begin{array}{c}\text { Patologias benignas } \\
\text { de pulmão, fibrose } \\
\text { cística. }\end{array}$ & $\begin{array}{c}\text { Alta especificidade para } \\
\text { carcinomas de pâncreas e } \\
\text { trato biliar }\end{array}$ \\
\hline CATEPSINA D & Câncer de mama & - & $\begin{array}{l}\text { Início e progressão do } \\
\text { processo metastático }\end{array}$ \\
\hline CEA & $\begin{array}{l}\text { Câncer colorretal } \\
\text { Trato Digestivo, } \\
\text { pulmão. }\end{array}$ & $\begin{array}{l}\text { Fumantes, cirrose, } \\
\text { doenças hepáticas. }\end{array}$ & $\begin{array}{l}\text { Prognóstico, avaliação de } \\
\text { tratamento. }\end{array}$ \\
\hline$C-E R B B-2$ & Câncer de mama & $\begin{array}{l}\text { Carcinomas de } \\
\text { pulmão }\end{array}$ & $\begin{array}{l}\text { Prognóstico de câncer de } \\
\text { mama }\end{array}$ \\
\hline CYFRA 21 & Câncer de pulmão & $\begin{array}{l}\text { Asma, pneumonias } \\
\text { tuberculose. }\end{array}$ & $\begin{array}{l}\text { Recorrência de tumor } \\
\text { primário }\end{array}$ \\
\hline PROTEÍNA P53 & Câncer de colorretal & - & $\begin{array}{c}\text { Iniciação e progressão } \\
\text { tumoral }\end{array}$ \\
\hline PRITEÍNA RB & $\begin{array}{l}\text { Câncer de } \\
\text { retinoblastoma }\end{array}$ & Câncer de pulmão & - \\
\hline NSE & Câncer de pulmão & $\begin{array}{c}\text { Tumores renais, } \\
\text { enfisemas e } \\
\text { pneumonias. }\end{array}$ & $\begin{array}{l}\text { Prognósticos e } \\
\text { monitoramento }\end{array}$ \\
\hline PCNA & Câncer de mama & $\begin{array}{l}\text { Câncer de bexiga, } \\
\text { melanomas. }\end{array}$ & Estadiamento e prognóstico \\
\hline PSA & Câncer de próstata & $\begin{array}{l}\text { Hiperplasia benigna } \\
\text { de próstata }\end{array}$ & $\begin{array}{l}\text { Triagem, diagnóstico e } \\
\text { seguimento de câncer de } \\
\text { próstata. }\end{array}$ \\
\hline TIREOGLOBULINA & Câncer de tireóide & $\begin{array}{l}\text { Adenomas, bócio } \\
\text { multinodular. }\end{array}$ & - \\
\hline
\end{tabular}

Quadro 1 - Principais marcadores tumorais utilizados na prática clínica.

Fonte: VAZ et al ${ }^{(5)}$

\section{ALFAFETOPROTEÍNA (AFP)}

A alfafetoproteína corresponde a uma glicoproteína com massa molecular de 69 a 70 kDa, com 590 aminoácidos e
4\% de resíduos de carboidratos, e com homologia parcial com albumina, que não contém açúcares. É uma importante proteína do soro fetal, sendo sintetizado no fígado, saco vitelino e intestino do 
De Oliveira, G. G., Da Fonseca, C. A. / Revista Eletrônica de Farmácia Vol VIII (2), 60 74,2011

feto. Desaparece nos primeiros anos de vida. Em indivíduos sadios, os valores de AFP são baixos, entre $5 \mathrm{ng} / \mathrm{mL}$ e $15 \mathrm{ng} / \mathrm{mL}$ sendo sintetizados no fígado e trato gastrointestinal, possui vida média de 5 a 7 dias. Níveis acima de $500 \mathrm{ng} / \mathrm{mL}$ são altamente sugestivos de malignidade, e valores acima de $1000 \mathrm{ng} / \mathrm{mL}$ são indicativos de presença de neoplasia(4).

A AFP encontra-se em quantidade elevada em tumores gastrintestinais, hepatite, cirrose hepatocarcinoma e gestantes. Pode ser encontrada em $70 \%$ das neoplasias testiculares não seminomatosos. É importante na monitoração da terapia do carcinoma de testículo, onde sua presença sugere persistência da doença e sua concentração sérica propicia uma estimativa do tempo de crescimento tumoral. Também é utilizado no diagnóstico de pacientes com carcinoma hepatocelular em conjunto com ultrasonografia abdominal ${ }^{(5)}$.

\section{ANTÍGENO CARCINOEMBRINÁRIO (CEA)}

Identificado em 1965 por Gold e Freedman, o Antígeno Carcinoembrinário (CEA) é uma glicoproteína de 200 kDa com funções desconhecidas, encontra-se sobre a superfície da membrana celular e normalmente em tecidos do aparelho digestivo e intestinal embrionário. Originalmente, foi descrito como presente em adenocarcinoma de cólon e reto, mas ausente em tecido colônico adulto normal. Seu valor de referência é de $3,5 \mathrm{ng} / \mathrm{mL}$ em não fumante, em fumantes $7 \mathrm{ng} / \mathrm{mL}^{(6)}$.

Em presença de neoplasia maligna, níveis elevados de CEA são detectados em $9 \%$ dos teratomas de testículo, e em aproximadamente $85 \%$ dos casos de carcinoma colorretal metastático. Níveis elevados também são encontrados nas neoplasias de pulmão (52\% a 77\%), pâncreas (61\% a $68 \%)$, trato gastrintestinal $(40 \%$ a $60 \%)$, trato biliar $(80 \%)$, tireóide $(50 \%$ a $70 \%)$, cérvice $(42 \%$ a $50 \%)$ e mama (30\% a 50\%). É útil na prática clínica do câncer gástrico sendo determinado no soro do paciente, na ocasião do diagnóstico e acompanhamento clínico, sendo importante na avaliação prognostica, apresenta em altas concentrações nos distúrbios benignos como cirrose alcoólica e doença de Crohn $^{(2)}$.

\section{ANTÍGENO PROSTÁTICO ESPECÍFICO (PSA)}

O Antígeno Prostático Específico, também denominado de Proteína específica para o tecido prostático, foi inicialmente descrito em 1971 por Hara e colaboradores, purificada, isolada e caracterizada por Wang em 1977. É o marcador tumoral de maior utilidade na prática clínica. Este é secretado no lúmen dos ductos prostáticos estando presente em grandes concentrações no 
De Oliveira, G. G., Da Fonseca, C. A. / Revista Eletrônica de Farmácia Vol VIII (2), 60 74,2011

líquido seminal (aproximadamente $2 \mathrm{ng} / \mathrm{mL}$ ). Aparentemente, teria a função de liquefazer o coágulo seminal. Seu nível sérico elevado, está associado com à transformação maligna do epitélio prostático. O PSA não é específico para o câncer de próstata, pois, pode ser encontrado em altas concentrações em outras situações, como: prostatite, hiperplasia prostática benigna (HPB), manipulação prostática e atividade sexual ${ }^{(1)}$.

A utilização do PSA é otimizada ao exame de toque retal que alcança $96 \%$ de sensibilidade para o diagnóstico, sendo que, valores maiores que $10 \mathrm{ng} / \mathrm{mL}$ de PSA associados aos sinais clínicos sugerem a realização de biópsia de próstata que confirma o diagnóstico de tumor primário. A determinação da concentração do PSA tem sido utilizada na prevenção da neoplasia prostática através de exames de rotina realizado anualmente por homens a partir de 50 anos de idade ${ }^{(5)}$.

\section{CANCER ANTIGEN 15.3}

O marcador CA 15.3 é classificado como mucina de elevada massa molecular (cerca de $400 \mathrm{kDa}$ ) produzida pelas células epiteliais glandulares. Seu valor normal de referência é de $25 \mathrm{U} / \mathrm{mL}$. É um marcador tumoral por excelência do câncer de mama, pois é mais sensível e específico. Seu valor sérico elevado varia de acordo com o estadiamento dos pacientes, sendo de $5 \%$ a $30 \%$ no estádio I, $15 \%$ a $30 \%$ no estádio II, $60 \%$ a $70 \%$ no estádio III, e de $65 \%$ a $90 \%$ no estádio IV. O aumento superior a $25 \%$ na sua concentração correlacionase com a progressão da doença em $80 \%$ a $90 \%$ dos casos, e a diminuição de sua concentração associa-se a regressão em $70 \%$ a $80 \%{ }^{(7)}$.

Níveis elevados de CA 15.3 podem ser observados em outras neoplasias, como: câncer de ovário, pulmão, colo uterino, hepatocarcinoma e linfomas. Também apresenta concentração elevada em doenças benignas como: hepatite crônica, tuberculose, sarcoidose e lúpus eritematoso sistêmico(5).

\section{CANCER ANTIGEN CA 19.9}

O CA 19.9 é um antígeno carboidrato de superfície celular, com peso molecular variando de $200 \mathrm{kDa} a$ $1000 \mathrm{KDa}$, sendo também conhecido como antígeno de Lewis. É liberado na superfície da célula cancerosa e penetra na corrente sanguínea, onde pode ser detectado. Seu valor normal de referência é $37 \mathrm{U} / \mathrm{mL}^{(8)}$.

Esse marcador é indicado no auxílio ao estadiamento e na monitoração de tratamentos. Apresenta-se em primeira escolha no câncer de pâncreas e trato biliar, em segunda escolha, no câncer colorretal. Possui sensibilidade de $70 \%$ a 94\% no câncer de pâncreas, 60\% a 79\% na neoplasia de vesícula biliar, 30\% a $50 \%$ no câncer gástrico e $40 \%$ a $60 \%$ na neoplasia colorretal. Também apresenta 
De Oliveira, G. G., Da Fonseca, C. A. / Revista Eletrônica de Farmácia Vol VIII (2), 60 74,2011

em menor freqüência, no câncer de mama, pulmão e de cabeça e pescoço, em algumas doenças benignas como: cirrose hepática, pancreatite, em doença inflamatória intestinal e doenças autoimunes $^{(1)}$.

A maior aplicabilidade desse marcador atualmente, é de avaliar resposta à quimioterapia do câncer de pâncreas, já que a utilização de métodos de imagem é bastante limitada para esse fim. No câncer colorretal, dados atuais são insuficientes para recomendar o uso rotineiro do CA 19.9 no rastreamento, diagnóstico e no acompanhamento do tratamento de pacientes portadores desta neoplasia ${ }^{(4)}$.

\section{CATEPSINA D}

A catepsina $D$ é uma endoprotease lisossomal ácida, identificada em linhagens de células de câncer de mama humano e estimulada por estrógeno, por Westley e Rochefort em 1980. É encontrado em todas as células dos mamíferos, esse marcador tumoral é muito estudado em câncer de mama. Embora a catepsina D apresenta ampla distribuição nos vários tipos de células humanas, existem diferenças quantitativas na sua distribuição tecidual. A função fisiológica da catepsina $D$ é desconhecida, mas parece estar envolvida na degradação das proteínas teciduais, tanto em condições normais quanto patológicas. O papel da catepsina $D$ na carcinogênese acredita- se estar associado à estimulação da síntese de DNA e mitose durante a regeneração tecidual e devido ao seu poder proteolítico, facilitaria a disseminação tumoral, por digestão de proteoglicanos da matriz intersticial e membrana basal ${ }^{(9)}$.

Estas evidências levaram à elaboração da hipótese de que a secreção da catepsina $D$ pelas células tumorais facilitaria a iniciação e progressão do processo metastático. Sendo assim, associa-se com a invasividade tumoral e a presença de metástases para linfonodos axilares. As altas concentrações associam-se com pior prognóstico de câncer de mama ${ }^{(1)}$.

\section{C-erbB-2}

O C-erbB-2 é uma oncoproteína com peso molecular de $185 \mathrm{KDa}$. Também denominado de HER-2, HER$2 /$ neu. Localiza-se no cromossomo $17 \mathrm{q}$, responsável pela codificação de uma glicoproteína transmembrana que atua como receptor de fator de crescimento (RFC) e apresenta atividade de quirosina quinase específica. Pode ser identificado, dosado em cultura ou liberado na circulação. Esse marcador é hiperexpresso em $20 \%$ a $40 \%$ dos carcinomas de mama(10).

A expressão aumentada de $C$-erbB2 é um indicador de prognóstico ruim, pacientes cujos tumores exibem expressão aumentada desse marcador 
De Oliveira, G. G., Da Fonseca, C. A. / Revista Eletrônica de Farmácia Vol VIII (2), 60 74,2011

apresentam sobrevida livre da doença menor. O C-erbB-2 apresenta também superexpresso em outras neoplasias humanas, incluindo câncer de pulmão de não-pequenas células. No adenocarcinoma de pulmão, o produto protéico do $C$-erbB-2 é observado em $28 \%$ a $38 \%$ dos casos, e associa-se com pior prognóstico. O produto protéico do $C_{-e r b B-2}$ é a proteína p185, uma glicoproteína transmembrana, que possui atividade tirosina-quinase e participa na transdução de sinal intracelular. Sua expressão em tecidos humanos normais é baixa e ocorre em menor freqüência. $A$ amplificação do protoncogene $C-e r b B-2$ também ocorre em $15-40 \%$ dos carcinomas primários de mama e 30\% dos carcinomas de ovário(11).

\section{CYFRA 21.1}

O CYFRA 21.1 é um antígeno formado por um fragmento da citoqueratina 19 de natureza ácida com $40 \mathrm{kDa}$, é específico de tecidos epiteliais simples de revestimento, membro de uma família de proteínas filamentosas que compõem o citoesqueleto celular é encontrado no soro. Na população, o nível de CYFRA 21.1 geralmente é inferior a $3,3 \mathrm{ng} / \mathrm{mL}$, por isso seu valor de referência é de $3,5 \mathrm{ng} / \mathrm{mL}^{(1)}$.

Esse marcador apresenta em altas concentrações em neoplasias de pulmão, sendo um fator de prognóstico ruim no carcinoma de células escamosas do pulmão. Encontra-se elevado em carcinoma pulmonar de pequenas células, câncer de bexiga (30\%), de colo de útero $(24 \%)$ de cérvice e de cabeça e pescoço (24\%). Foram demonstrados aumentos inespecíficos em várias situações, como doenças pulmonares benignas (asma, pneumonias, tuberculose e pneumonites) em até $4 \%$ dos casos e em patologias sistêmicas como a cirrose e insuficiência renal. Ensaios mensais ou trimestrais permitem detectar precocemente as recorrências do tumor primário ou mesmo as suas metástases, uma vez que o CYFRA 21.1 exibe uma alta correlação com a resposta clínica a qualquer tratamento instituído, desde que seja eficaz ${ }^{(5)}$.

\section{PROTEÍNA P53}

O gene supressor de tumor TP53 localiza-se no cromossomo 17, codifica uma fosfoproteína denominada P53, a proteína $\mathrm{P} 53$ é considerada como elemento chave na carcinogênese devido à sua função supressora de tumores através da detecção e correção de mutações gênicas. Atua na regulação do ciclo celular, reparo do DNA e dependendo da extensão da lesão, induz a apoptose (morte celular programada) de células geneticamente instáveis, dessa forma, matem a integridade do genoma ${ }^{(12)}$.

Mutações e inativações do gene TP53 são as alterações genéticas mais freqüentes nos tumores malignos humanos, ocorrendo em cerca de $50 \%$ 
De Oliveira, G. G., Da Fonseca, C. A. / Revista Eletrônica de Farmácia Vol VIII (2), 60 74,2011

das neoplasias de vários órgãos como: pulmão, mama, ovário. Geralmente, as mutações no gene TP53 coincidem com o aparecimento de tumores biologicamente agressivos e com a perda da diferenciação celular, no tumor anaplásico de Wilms, tumor de tireóide, glioma maligno ou anaplásico, melanoma metastático e invasivo, e câncer de próstata. A imunoexpressão do gene TP53 pode ter valor prognóstico desfavorável em pacientes com câncer retal, pois, índice elevado da proteína p53 demonstra tumores com maior envolvimento linfonodal. Nos casos de tumores positivos para o gene TP53, quando comparada aos casos negativos constatou-se uma sobrevivência menor do que 5 anos $^{(13)}$.

A proteína p53 é metabolicamente lábil. A forma mutante dessa proteína exibe um aumento de sua meia-vida, podendo ser detectada por técnicas imuno-histoquímicas em muitos tumores (14)

\section{PROTEÍNA RB}

Identificado por Friend e colaboradores em 1986, como gene supressor de tumor. Está relacionado com o câncer de retinoblastoma que acomete principalmente crianças, correspondendo a 2 a $4 \%$ dos tumores malignos pediátricos. Tem uma incidência de 11 casos novos por milhão em menores de cinco anos nos Estados Unidos $(1: 18.000$ nascidos vivos $=200$ casos/ano), sem diferença entre sexo ou raça ${ }^{(4)}$.

O câncer de retinoblastoma é o $4^{\circ}$ tumor mais freqüente em crianças até 14 anos de idade, $80 \%$ são diagnosticados antes dos 3 e 4 anos de idade e 30 a $40 \%$ são bilaterais esse câncer desenvolve-se em conseqüência de mutações ou perda de um dos alelos desse gene, que exerce uma função supressora sobre a proliferação do ciclo celular $^{(15)}$.

Os sintomas que chamam atenção para o diagnóstico precoce do retinoblastoma levando ao encaminhamento ao oftalmologista são: reflexo do olho de gato (leucocoria), massa orbitária, estrabismo, cor diferente dos olhos (heterocromia), hiperemia conjuntival, cefaléia, vômitos, dor óssea e perda de visão(15).

\section{NSE (ENOLASE NEURÔNIO- ESPECÍFICO)}

Descrita inicialmente em 1965 por Moore e McGregor como enzima catalisadora da via glicolítica anaeróbia, a NSE é a forma neuronal da enzima glicolítica enolase, é encontrada quase exclusivamente nos neurônios e nas células de origem neuroendócrina, existindo em quantidades desprezíveis no sangue periférico. É uma forma dimérica composta por duas subunidades $Y$, que faz a conversão do 2-fosfoglicerato em fosfoenolpiruvato. As concentrações encefálicas de NSE variam 
De Oliveira, G. G., Da Fonseca, C. A. / Revista Eletrônica de Farmácia Vol VIII (2), 60 74,2011

de $0,4 \%$ a $2,2 \%$ e podem representar até $4 \%$ do total de proteínas solúveis em alguns neurônios. Em cérebros adultos, altas concentrações de NSE são encontradas na substância cinzenta, ao passo que são baixas as concentrações na substância branca. Tem alta estabilidade em fluidos biológicos e pode difundir-se facilmente do meio extracelular para o líquor, podendo, então, ser mensurada nesse líquido e no sangue, Possui meia-vida de aproximadamente $24 \mathrm{~h}^{(1)}$.

É útil também como indicador de prognóstico da extensão da isquemia cerebral em pacientes em coma pósparada cardiorrespiratória, em patologias benignas como enfisemas e pneumonias podem apresentar níveis séricos elevados em $10 \%$ dos casos, possui aplicação de monitorar pacientes em tratamento quimioterápico, pois seus valores séricos tendem a subir ou baixar de acordo com a resposta à terapia empregada e até antever recidiva da doença $^{(5)}$.

\section{PCNA}

O Antígeno nuclear de proliferação celular (PCNA) é uma proteína de $36 \mathrm{kDa}$ associada a atividade proliferativa, auxilia a DNA-polimerase-delta que atua na replicação e no reparo de moléculas de DNA lesadas através da excisão de nucleotídeos formando um complexo quaternário com a proteína P21, a ciclina $D$ e a CDK (quinase dependente de ciclina) sua presença pode ser observada no ciclo celular na fase $S$ e declina na fase $G_{2}$ e $M^{(16)}$.

Esse marcador é útil como indicador de prognóstico em carcinomas de células escamosas oral, carcinomas cervicais, melanomas metastáticos, carcinomas epidermóides do trato aerodigestivo superior, neoplasias de bexiga e mama. Também possui associação com o grau, sobrevida e progressão da doença. No câncer de mama o nível elevado de PCNA relaciona-se com tumores bem diferenciados e não diferenciados, pois, os tumores diferenciados, tendem a ter baixo índice de proliferação, enquanto que, os não diferenciados ou de alto grau demonstram ter um alto índice de proliferativo $^{(13)}$.

\section{TIREOGLOBULINA (TG)}
A tireoglobulina (TG) é uma glicoproteína de alto peso molecular 660 $\mathrm{kDa}$, fundamental para síntese $\mathrm{e}$ armazenamento de hormônio tireoidiano. A TG é sintetizada exclusivamente pelas células foliculares tiroidianas, é iodedada em seus radicais tirosila que será o maior estoque de hormônios tireoidianos, os quais serão liberados por proteólise. Uma vez na circulação, a meia-vida da TG é de 3 a 65 horas, dependendo do grau de modificações pós-traducionais, sua metabolização é feita primariamente pelo fígado( ${ }^{(17)}$.

A tireoglobulina é útil no acompanhamento dos pacientes após 
De Oliveira, G. G., Da Fonseca, C. A. / Revista Eletrônica de Farmácia Vol VIII (2), 60 74, 2011

terapêutica do câncer. Em geral, quanto maior a massa de tecido tireoidiano remanescente (normal ou neoplásico) maior o nível de Tireoglobulina sérica. Desta forma, nos pacientes submetidos à terapia ablativa (cirurgia + dose ablativa de iodo 131) a TG sérica permanece indetectável numa maior proporção de casos em relação aos pacientes tratados de forma mais conservadora(18).

Pode ser observada a utilização desse marcador em recorrências de tumores tireoidiano ou metástases linfonodais, pois $26 \%$ dos pacientes diagnosticados apresentam valores de tireoglobulina entre 1 a $5 \mathrm{ng} / \mathrm{ml}$. Valores de TG entre 5 a $10 \mathrm{ng} / \mathrm{ml}$ associam-se a metástases distantes em 14,2\% dos casos, com os demais apresentando doença cervical ou mediastinal. Metástases distantes foram detectadas em $51,3 \%$ dos pacientes com valores de TG maior do que $10 \mathrm{ng} / \mathrm{mL}^{(17)}$

\section{DETECÇÃO DE MARCADORES TUMORAIS POR IMUNO- HISTOQUÍMICA}

A Imuno-histoquimica é a principal técnica para detectar marcadores tumorais, possui a capacidade de reconhecer constituintes celulares, ou seja, antígenos, e assim identificar e classificar células específicas dentro de uma população celular morfologicamente homogenia ou aparentemente heterogenia. A visualização do complexo antígenoanticorpo é possível pela adição de um fluorocromo (conjugado) ao anticorpo que pode ser identificado pelo microscópio, alternativamente pode ser uma enzima na qual o produto da reação pode ser visualizado(2).

A técnica de imuno-histoquímica pode ser direta quando os anticorpos são ligados a marcadores apropriados ao corte de tecido que contem proteínas, estas são incubadas com o antígeno durante algum tempo. Após a interação dos anticorpos ocorre uma lavagem para retirar todo o anticorpo não ligado. Se o marcador utilizado for fluorescente, como acontece na imuno-histoquímica de fluorescência o corte é observado ao microscópio de luz. A forma indireta refere-se à detecção de anticorpos no soro do paciente utilizando um segundo anticorpo anti-Ig marcado, o complexo enzimático avidina-biotina-enzima. O complexo é formado pela ligação de uma molécula de (strept) avidina com várias de biotina associadas a uma enzima (peroxidase fosfatase alcalina), que tem como função a conversão de um cromógeno incolor em um produto que pode conferir diversas cores aos antígenos teciduais marcados ${ }^{(19)}$.

O cromógeno mais utilizado é o DAB (diaminobenzidina) que confere cor marrom ao precipitado permanente logo, as áreas "positivas" coram-se de marrom e as "negativas", coram com o corante utilizado para contra-coloração, geralmente a hematoxilina de cor azul. 
De Oliveira, G. G., Da Fonseca, C. A. / Revista Eletrônica de Farmácia Vol VIII (2), 60 74, 2011

Atualmente há disponibilidade de grande número de anticorpos primários para uso em tecidos fixados em formol e incluídos em blocos de parafina, permitindo o exame imuno-histoquímica de biópsias, peças cirúrgicas e de necropsias arquivados por muitos anos. Preparados citopatológicos também podem ser utilizados nos exames imunohitoquímicos ${ }^{(20)}$.

\section{CONCLUSÃO}

Esse estudo de revisão levantou dados bibliográficos sobre os marcadores tumorais. Com base na literatura ressaltou-se a importância da utilização dos marcadores tumorais no manejo clínico de pacientes com câncer. Sendo estes fundamentais no diagnóstico precoce da doença, através de sua constatação nas células e tecidos com diferenciação neoplásica, também podem apresentar em altas concentrações nos líquidos biológicos sendo facilmente quantificados por exames laboratoriais como: o PSA (Antígeno Prostático Específico) realizado para identificar o câncer de próstata que permite caracterizar alterações neoplásicas. Também é importante no diagnóstico do estágio da doença, assim, como na identificação de presença de metástase.

A utilização dos marcadores tumorais no direcionamento de terapias antineoplásicas é importante, pois, quando os marcadores estão presentes em determinada neoplasia, possibilita ao oncologista definir a terapia mais adequada aquele tipo de neoplasia, assim, proporciona aos pacientes maiores chances de controle e cura da doença.

A técnica de imuno-histoquímica empregada na detecção dos marcadores tumorais abordada nessa revisão possibilita detectar com segurança diversos marcadores, no entanto, dado ao grande número de marcadores tumorais conhecidos $\mathrm{e}$ as diferentes formas de detecção de cada um com suas variáveis, é essencial que protocolos sejam padronizados internacionalmente para que tais marcadores sejam detectados sem diferentes variações.

\section{REFERÊNCIAS BIBLIÓGRAFICAS}

1. Almeida JR, C, Lima NP, Leite JB, Fleming TR, P, Carvalho VH, Cardoso A. Marcadores tumorais: Revisão de literatura. Rev. bras. de cancero.2007;53(3):305-316.

2. Matos L. et al. Tecnologia aplicada na detecção de marcadores tumorais. Arq. Med. do ABC. $2005 ; 30(1): 19-25$. 
De Oliveira, G. G., Da Fonseca, C. A. / Revista Eletrônica de Farmácia Vol VIII (2), 60 74,2011

3. Reis C. J. F. Rastreamento e diagnóstico de neoplasias de ovário-papel dos marcadores tumorais. tumorais. Rev. Bras. Ginecol. Obstet.2005;27(4)222-227.

4. Mattar R, Andrade CR, DiFavero GM, Gama-Rodrigues JJ, Laudanna AA. Preoperative Serum Levels Of CA 72-4, CEA, CA 19-9, And Alpha Fetoprotein In Patients With Gastric Cancer. Rev. Hosp. Clin. Fac. Med. S.Paulo. 2002;57(3):89-92

5. Vaz, J. A et al. Imunoensaios Fundamentos e Aplicações: Ciências farmacêuticas Rio de Janeiro: Guanabara Koogan, 2007.

6. Polycarpo, A. et al. Determinação do antígeno carcinoembrionário biliar na detecção das metástases hepáticas do carcinoma colorretal. Acta Cir. Bras.2003;18(4):4-9.

7. Guimarães R. C. et al. Uso de marcadores tumorais na prática clínica. Rev. Prát. Hosp. $2002 ; 4(23): 10-18$.

8. Figueiredo, L. C et al. Câncer de pele: estudo dos principais marcadores moleculares do melanoma cutâneo. Rev. Bras. de Cancero.2003;49(3):179-183.

9. Borges et al. Asociación de catepsina $D$ con factores pronósticos en melanoma maligno. Rev. venez. Oncol.2005;27(3):13-140.

10. Sales OA, Rodrigues SJ, Paiva BC. Estudo comparativo entre os métodos LSAB+ e Herceptest para a detecção de HER-2/neu em carcinoma de mama. J. Bras. Patol. Med. Lab.2004;40(4): 265-271

11. Pacheco, AF, Paschoal ME, M, Carvalho MG, C. et al. Marcadores tumorais no câncer de pulmão: um caminho para a terapia biológica. J. Pneumologia. 2002;28(3): 143-149. 
De Oliveira, G. G., Da Fonseca, C. A. / Revista Eletrônica de Farmácia Vol VIII (2), 60 74,2011

12. Alves, S. T. M et al. Osteossarcomas humanos de alto grau: imunoexpressão de $p 53$, erb-2 e p-glicoproteína, e correlação com o parâmetro anaplasia. J. Bras. Patol. Med. Lab.2008;44(2):107-114.

13. Novellino A. T. N., Amorim R. Fernandes B.Q., Freitas R.A. Análise da imunoexpressão do PCNA e p53 em carcinoma de células escamosas oral: correlação com a gradação histológica de malignidade e características clínicas. Acta Cir. Bras.2003;18(5):458-494.

14. Felin, CR, Rocha A.B, Felin IP,D, Regner A, Grivicich T. Expressão das proteínas p53 e Cox 2 em adenocarcinoma intestinal e mucosa adjacente. Rev bras. coloproctol. $2008 ; 28(1): 19-25$.

15. Antoneli, G. B. C. et al. Evolução da terapêutica do retinoblastoma. Arq. Bras. Oftalmol. 2003;1(66):401-408.

16. Neto J. A. D., Martins A. C. P., Maggione G., Tucci Jr S., Cologna A. J., Suaid H. J.. Antígeno nuclear de proliferação celular (pcna) em carcinoma de células transicionais de bexiga. Acta Cir. Bras. 2001;16(1):435-439.

17. Matsuo, ES et al. Marcadores Biológicos de tumores tiroidianos. Arq Bras Endocrinol Metab.2004;48(1):1-12.

18. Coelho, MS, Vaisman MC, Pires D. Amplificação de mRNA de tireoglobulina no sangue de pacientes com carcinoma diferenciado da tireóide: Qual o seu verdadeiro significado? Arq Bras Endocrinol Metab. 2006;50(3):427-435.

19. Capellozi, V. L. Papel da imuno-histoquímica no diagnóstico do câncer de pulmão. J. bras. pneumol.2009;35(4):375-382. 
De Oliveira, G. G., Da Fonseca, C. A. / Revista Eletrônica de Farmácia Vol VIII (2), 60 74, 2011

20. Rocha AO, Coutinho LM,B, Leboute LD, scholl JG. Expressão imuno-histoquimica e valor prognóstico da proteína p53 no carcinoma de vesícula biliar: estudo de 60 casos. J. Bras. Patol. Med. Lab.2004; 40(6): 403-410. 